\title{
Prognostic significance of circumferential resection margin involvement following oesophagectomy for cancer and the predictive role of endoluminal ultrasonography
}

\author{
TD Reid', DSY Chan', SA Roberts ${ }^{2}$, TDL Crosby ${ }^{3}$, GT Williams ${ }^{4}$ and WG Lewis ${ }^{*}, 1$ \\ 'Department of Surgery, South East Wales Cancer Network, University Hospital of Wales, Heath Park, Cardiff CFI4 4XW, UK; ${ }^{2}$ Department of \\ Radiology, South East Wales Cancer Network, University Hospital of Wales, Cardiff, UK; ${ }^{3}$ Department of Oncology, Velindre Hospital, Cardiff, UK; \\ ${ }^{4}$ Department of Pathology, South East Wales Cancer Network, University Hospital of Wales, Heath Park, Cardiff, UK
}

\begin{abstract}
BACKGROUND: The optimum multimodal treatment for oesophageal cancer, and the prognostic significance of histopathological tumour involvement of the circumferential resection margin $(C R M+)$ are uncertain. The aims of this study were to determine the prognostic significance of CRM + after oesophagectomy and to identify endosonographic (endoluminal ultrasonography (EUS)) features that predict a threatened CRM+.

METHODS: Two hundred and sixty-nine consecutive patients underwent potentially curative oesophagectomy (I 03 surgery alone, I 24 neoadjuvant chemotherapy (CS) and 42 chemoradiotherapy (CRTS)). Primary outcome measures were disease-free survival (DFS) and overall survival (OS).

RESULTS: CRM + was reported in 98 (38.0\%) of all, and in 90 (62.5\%) of pT3 patients. Multivariate analysis of pathological factors revealed: Iymphovascular invasion (HR 2.087, 95\% Cl I.396-3.122, P<0.000I), CRM + (HR I.762, 95\% Cl I.20I-2.586, P=0.004) and lymph node metastasis count (HR I.563,95\% Cl I.018-2.400, P=0.04I) to be independently and significantly associated with DFS. Lymphovascular invasion (HR 2.160,95\% Cl I.432-3.259, P<0.00I) and CRM + (HR I.5। 4, 95\% Cl I.000-2.292, P=0.050) were also independently and significantly associated with OS. Multivariate analysis revealed EUS T stage (T3 or T4, OR 24.3। 3, 95\% $\mathrm{Cl} 7.438-79.476, P<0.000 \mathrm{I}$ ) and use or not of CRTS (OR 0.1 I6, 95\% Cl 0.035-0.382, P<0.000I) were independently and significantly associated with CRM+.

CONCLUSION: A positive CRM was a better predictor of DFS and OS than standard PTNM stage. British Journal of Cancer (2012) I07, 1925-1931. doi:I0.1038/bjc.2012.5 I w www.bjcancer.com Published online 20 November 2012

(c) 2012 Cancer Research UK
\end{abstract}

Keywords: oesophageal cancer; oesophagectomy; circumferential resection margin; neoadjuvant chemotherapy; neoadjuvant chemoradiotherapy

Pathological involvement of the circumferential resection margin $(\mathrm{CRM}+)$ after rectal cancer surgery is a well-established prognostic indicator (Adam et al, 1994), and patients deemed on radiological criteria to be at risk of a threatened CRM are offered preoperative chemoradiotherapy (Klautke et al, 2005). In contrast, the prognostic significance of CRM + after oesophageal cancer surgery is less certain and the literature polarised. The overall reported incidence of $\mathrm{CRM}+$ ranges from 20 to 50\% (Sagar et al, 1993; Dexter et al, 2001; Khan et al, 2003; Griffiths et al, 2006; Sujendran et al, 2008; Thompson et al, 2008; Deeter et al, 2009; Saha et al, 2009; Scheepers et al, 2009; Mirnezami et al, 2010; Pultram et al, 2010; Chao et al, 2011; Verhage et al, 2011; Harvin et al, 2012; Rao et al, 2012; Salih et al, 2012), and in the most recent UK national oesophagogastric audit was reported to be $29 \%$ (NHS Information Centre, 2010).

Sagar et al (1993) first reported an association between CRM + and local recurrence after oesophagectomy, and several studies have since examined the influence of CRM + on survival (Dexter et al, 2001;

*Correspondence: WG Lewis; E-mail: wyn.lewis4@wales.nhs.uk Received 27 July 2012; revised 17 October 2012; accepted 22 October 2012; published online 20 November 2012
Khan et al, 2003; Griffiths et al, 2006; Sujendran et al, 2008; Thompson et al, 2008; Deeter et al, 2009; Saha et al, 2009; Scheepers et al, 2009; Mirnezami et al, 2010; Pultram et al, 2010; Chao et al, 2011; Verhage et al, 2011; Harvin et al, 2012; Rao et al, 2012; Salih et al, 2012). Although some report an independent negative association between CRM + and survival (Dexter et al, 2001; Griffiths et al, 2006; Sujendran et al, 2008; Deeter et al, 2009; Saha et al, 2009; Scheepers et al, 2009; Pultram et al, 2010; Verhage et al, 2011), others have not (Khan et al, 2003; Thompson et al, 2008; Mirnezami et al, 2010; Chao et al, 2011; Harvin et al, 2012; Rao et al, 2012; Salih et al, 2012).

Most UK oesophageal cancer patients present with locoregional advanced disease, and the aim of neoadjuvant therapy is to increase the probability of potentially curative (R0) resection. Following the publication of MRC OE02, contemporary optimum treatment in the United Kingdom has been considered to be neoadjuvant chemotherapy (CS) followed by surgery (Medical Research Council Oesophageal Cancer Working Group, 2002), but less than $30 \%$ of patients are suitable (NHS Information Centre, 2010), and for those that are, 5-year survival remains poor at just 23\% (Allum et al, 2009). Neoadjuvant chemoradiotherapy has been reported to downstage tumours in over $90 \%$ of patients (Reynolds et al, 2007), facilitating R0 resection, but has fallen out of favour in 
the United Kingdom because of concerns regarding associated serious operative morbidity, allied to $\mathrm{OE} 02$ trial publication promoting CS. Preoperative radiological risk assessment of a circumferentially incomplete (R1) resection, based on endoluminal ultrasonography (EUS), could potentially inform the choice of neoadjuvant therapy, but this possibility has yet to be examined. The aims of this study were three-fold: to identify the relative prognostic significance of $\mathrm{CRM}+$ after potentially curative oesophagectomy; to assess the predictive value of EUS in determining whether the CRM is likely to be threatened; and to examine the relative influence of specific neoadjuvant modalities on CRM + status.

\section{MATERIALS AND METHODS}

Consecutive patients treated for oesophageal cancer between 1 January 1998 and 29 February 2012, by the regional SE Wales upper GI cancer network, were studied. Patients were excluded if they had been treated for high-grade dysplasia in the absence of invasive malignancy, if open and close surgery had been performed (aborted resection), if there was pathological involvement of the longitudinal resection margins, or if pathological tumour nodes metastasis stage information was missing. Patients were also excluded if they underwent salvage surgery following definitive chemoradiotherapy. No patients had synchronous or metachronous ENT carcinomas. After exclusions, 269 patients underwent potentially curative oesophagectomy, and form the basis of this study (Figure 1). Clinical, radiological and pathological information was collected on a prospectively maintained database. Preoperative staging was in accordance with the UICC Tumour Nodes Metastasis 6th Edition, and involved computed tomography and EUS in all patients, and also laparoscopy if appropriate. More recently, CT-PET has been utilised for patients diagnosed since January 2009. All EUS examinations were either performed or supervised by a single radiologist and the details of the technique used have been reported previously (Weaver et al,

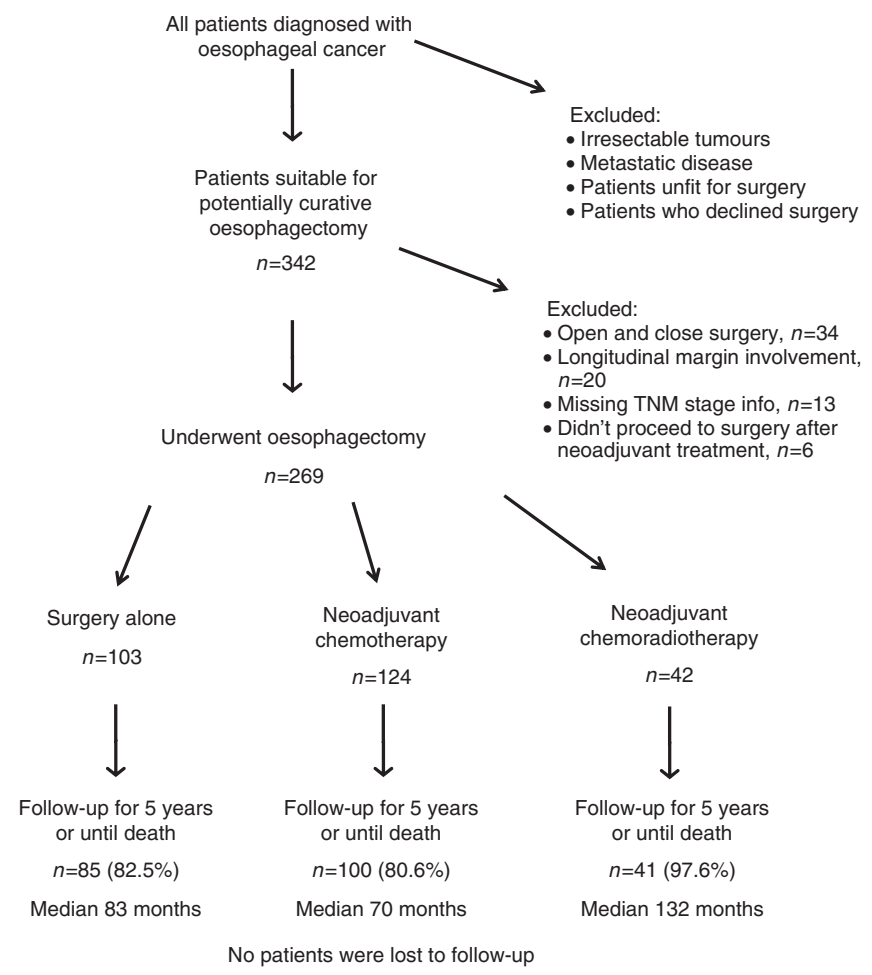

Figure I Patient flow diagram.
2004). The slim Olympus (Olympus UK, Southend on Sea, UK) MH-908 probe was used where necessary to ensure a high proportion of tumours were crossed at EUS. Dilatation to facilitate EUS was performed but only very occasionally.

\section{Surgery $+I-$ neoadjuvant therapy}

All patients had individually tailored management plans. In general, fit patients with tumours of stage T3/T4, N0 and N1, or T1/T2 N1 were considered for neoadjuvant therapy. Before 2002 patients were treated with neoadjuvant chemoradiotherapy. They received two cycles of cisplatin $\left(60 \mathrm{mg} \mathrm{m}^{-2}\right)$ with $300 \mathrm{mg} \mathrm{m}^{-2}$ per day of infusional 5-fluorouracil (5-FU) before 45-Gy radiotherapy delivered in 25 fractions. Following the publication of the OE02 trial, patients were treated with CS. They received either two cycles of cisplatin $\left(80 \mathrm{mg} \mathrm{m}^{-2}\right)$ and 5-FU $\left(1000 \mathrm{mg} \mathrm{m}^{-2}\right)$ or four cycles of epirubicin $\left(50 \mathrm{mg} \mathrm{m}^{-2}\right)$, cisplatin and 5 -FU $\left(200 \mathrm{mg} \mathrm{m}^{-2}\right)$. The operative approach was transthoracic for 157 (58.4\%) patients, and transhiatal for $112(41.6 \%)$. Transhiatal surgery was employed selectively for patients with early-stage tumours of the lower third of the oesophagus, with poorer performance status, in whom it was considered that a thoracotomy may carry an unacceptable risk of respiratory complications. All surgery was performed by specialist upper GI surgeons. Oesophageal resection was defined as potentially curative when all visible tumour had been removed and both proximal and distal resection margins were free from tumour on histological examination. Operative mortality was defined as death occurring within 30 days of surgery. No patients in this study received adjuvant therapy.

\section{Circumferential margin assessment}

Pathological involvement of the CRM + was defined according to the Royal College of Pathologists, as the presence of tumour within $1 \mathrm{~mm}$ of the circumferential margin (Mapstone, 2007). Reporting of CRM status was based on best practice at the time, guided by the first (Mapstone, 1998), and second (Mapstone, 2007) editions of the Royal College of Pathologists' Dataset for the histopathological reporting of oesophageal carcinoma.

\section{Follow-up and disease recurrence}

Patients were reviewed every 3 months for the first year and then 6 monthly thereafter. Where disease recurrence was suspected it was confirmed with investigations, usually CT or endoscopy. The time of recurrence was taken as the date of the confirmatory investigation. Death certification was obtained from the Office for National Statistics.

\section{Statistical analysis}

Grouped data were expressed as median (range) and nonparametric methods used for comparison. Comparison of categorical variables was performed with the $\chi^{2}$ test, and comparison of continuous variables with the Mann-Whitney $U$-test. Median follow-up was calculated using the reverse Kaplan-Meier method. Overall survival was calculated in months from the date of diagnosis. Disease-free survival was also calculated in months from the date of diagnosis, with either the confirmation of disease recurrence or death constituting the end point. Cumulative survival was calculated according to the life-table method of Kaplan and Meier, and differences between groups were analysed with the log-rank test. Univariate and multivariate survival analyses were performed using Cox regression. Univariate and multivariate analyses of pre-treatment factors influencing CRM status were performed using binary logistic regression. Statistical tests were two-sided and the level of significance taken as 0.05 . 
All data analysis was performed using the Statistical Package for the Social Sciences version 18 (SPSS, Chicago, IL, USA).

\section{RESULTS}

The clinical and radiological details of the patients related to neoadjuvant treatment type are shown in Table 1, and pathological details in Table 2. There were progressive increases in the radiological $\mathrm{T}$ and $\mathrm{N}$ stages of the patients treated between the surgery alone, CS and neoadjuvant chemoradiotherapy groups. A complete pathological response occurred in more than one-third of patients who received chemoradiotherapy, but was a relatively rare event in those treated with chemotherapy. For all patients the median lymph node harvest was $12(0-41)$, and the median number of lymph node metastases was 1 (0-18). CRM status was reported in $258(96.0 \%)$ patients, of which $98(38.0 \%)$ were $\mathrm{CRM}+$.

\section{Follow-up}

Follow-up until 5 years or death was available for 226 (84.0\%) patients. The median follow-up was 88 months (range 4-157).

\section{Survival related to CRM status for all patients}

A negative CRM (CRM - ) was associated with significantly better DFS (median: 63 vs 19 months, 2 year: 67.1 vs 36.7\%, $P<0.0001$ ) and overall survival (OS; median: 66 vs 26 months, 2 year: $70.8 v s$ $55.5 \%, P<0.0001)$. Figure 2 demonstrates DFS related to CRM status for all patients and Figure 3 for patients with pT3 stage. In this pT3 subgroup CRM - was associated with significantly better DFS (median: 30 vs 20 months, 2 year: 60.3 vs 39.3\%, $P=0.019$ ) and OS (median: 36 vs 28 months, 2 year: 66.1 vs 59.9\%, $P=0.032$ ) when compared with $\mathrm{CRM}+$.

Table I Details of the patients

\begin{tabular}{|c|c|c|c|c|}
\hline & $\mathbf{s}$ & CS & CRTS & $P$-value \\
\hline Number & 103 & 124 & 42 & \\
\hline Gender, M:F & $79: 24$ & $98: 26$ & $31: 11$ & $0.769^{a}$ \\
\hline Median age in years (range) & $66(35-79)$ & $62(36-74)$ & $55(3|-7|)$ & $<0.0001^{b}$ \\
\hline Histology, ACC:SCC & $79: 24$ & $103: 21$ & $30: 12$ & $0.224^{\mathrm{a}}$ \\
\hline \multicolumn{4}{|l|}{ EUS T stage } & $<0.0001^{a}$ \\
\hline $\mathrm{TI}$ & $26(25.2)$ & $2(1.6)$ & 0 & \\
\hline T2 & $33(32.0)$ & $12(9.7)$ & | (2.4) & \\
\hline T3 & $43(41.7)$ & $96(77.4)$ & $34(81.0)$ & \\
\hline T4 & | (1.0) & $10(8.1)$ & $7(16.7)$ & \\
\hline Not crossed & 0 & $4(3.2)$ & 0 & $0.093^{\mathrm{a}}$ \\
\hline \multicolumn{4}{|l|}{ EUS N stage } & $<0.0001^{a}$ \\
\hline No & $70(68.0)$ & $45(36.3)$ & $10(23.8)$ & \\
\hline $\mathrm{NI}$ & $33(32.0)$ & $75(60.5)$ & $32(76.2)$ & \\
\hline Not crossed & 0 & $4(3.2)$ & 0 & $0.093^{\mathrm{a}}$ \\
\hline EUS MIa & $2(1.9)$ & $5(4.0)$ & $3(7.1)$ & $0.314^{\mathrm{a}}$ \\
\hline EUS tumour length (range) & $3(0-15)$ & $5(1-12)$ & $5(|-| \mid)$ & $<0.0001^{\mathrm{b}}$ \\
\hline EUS disease length (range) & $3(0-15)$ & $7(1-19)$ & $5(1-16)$ & $<0.0001^{b}$ \\
\hline $\begin{array}{l}\text { EUS tumour thickness in } \\
\text { (range) }\end{array}$ & $0.9(0-1.7)$ & $1.3(0.5-3.0)$ & $(0.5-2.0)$ & $<0.0001^{b}$ \\
\hline
\end{tabular}

Abbreviations: $\mathrm{ACC}=$ adenocarcinoma; $\mathrm{CRTS}=$ neoadjuvant chemoradiotherapy; $\mathrm{CS}=$ neoadjuvant chemotherapy; $\mathrm{EUS}=$ endoluminal ultrasonography; $\mathrm{F}=$ female; $\mathrm{M}=$ male; $\mathrm{S}=$ surgery alone; $\mathrm{SCC}=$ squamous cell carcinoma. Stage figures are numbers (\%). Length and thickness parameters are median $\mathrm{cm}$ (range). ${ }^{\mathrm{a}} \chi^{2}$ test. bMann-Whitney $U$-test. Italic values indicate $P<0.000$ I
Table 2 Pathological details of the patients

\begin{tabular}{|c|c|c|c|c|}
\hline & $\mathbf{S}$ & CS & CRTS & $P$-value \\
\hline Number & 103 & 124 & 42 & \\
\hline CPR & NA & $3(2.5)$ & $15(35.7)$ & $<0.0001^{\mathrm{a}}$ \\
\hline pT stage & & & & $<0.0001^{a}$ \\
\hline $\mathrm{TI}^{\circ}$ & $34(33.0)$ & $9(7.3)$ & $4(9.5)$ & \\
\hline $\mathrm{T} 2$ & $18(17.5)$ & $20(16.1)$ & $6(14.3)$ & \\
\hline T3 & $50(48.5)$ & $88(71.0)$ & $15(35.7)$ & \\
\hline T4 & I (1.0) & $4(3.2)$ & $2(4.8)$ & \\
\hline pN stage & & & & $<0.0001^{a}$ \\
\hline No & $56(54.4)$ & $42(33.9)$ & $30(71.4)$ & \\
\hline $\mathrm{NI}$ & $47(45.6)$ & $82(66.1)$ & $12(28.6)$ & \\
\hline Tumour grade & & & & $0.087^{\mathrm{a}}$ \\
\hline Well & $13(12.6)$ & $8(6.5)$ & I (2.4) & \\
\hline Moderate & $52(50.5)$ & $54(43.5)$ & $9(21.4)$ & \\
\hline Poor & $29(28.2)$ & $54(43.5)$ & II (26.2) & \\
\hline Not reported & $9(9.4)$ & $5(4.0)$ & $6(14.3)$ & \\
\hline CRM & & & & $<0.0001^{a}$ \\
\hline Negative & $67(65.0)$ & $57(46.0)$ & $36(85.7)$ & \\
\hline Positive & $30(29.1)$ & $63(50.9)$ & $5(12.0)$ & \\
\hline Not reported & $6(5.8)$ & $4(3.2)$ & I (2.4) & \\
\hline LV invasion & & & & $0.011^{\mathrm{a}}$ \\
\hline No & $49(48.0)$ & $57(48.0)$ & $27(64.3)$ & \\
\hline Yes & $31(30.1)$ & $55(44.4)$ & $7(16.7)$ & \\
\hline Not reported & $23(22.3)$ & $12(9.7)$ & $8(19.0)$ & \\
\hline \multicolumn{5}{|l|}{ LNs } \\
\hline Median LNMC & $0(1-13)$ & I (0-18) & $0(0-6)$ & $<0.0001^{b}$ \\
\hline Median LN harvest & $10(2-41)$ & $13.5(1-38)$ & $10(0-39)$ & $0.001^{b}$ \\
\hline
\end{tabular}

Abbreviations: $C P R=$ complete pathological response to neoadjuvant therapy; $C R M=$ circumferential resection margin; CRTS = neoadjuvant chemoradiotherapy; $C S=$ neoadjuvant chemotherapy; $L N=$ lymph node; $L N M C=$ lymph node metastasis count; $\mathrm{LV}=$ lymphovascular; $\mathrm{NA}=$ not applicable; $\mathrm{S}=$ surgery alone. All figures are numbers (\%), with the exception of lymph node counts, which are median (range). ${ }^{a} \chi^{2}$ test. ${ }^{b}$ Mann-Whitney $U$-test. Italic values indicate $P<0.000$ I.

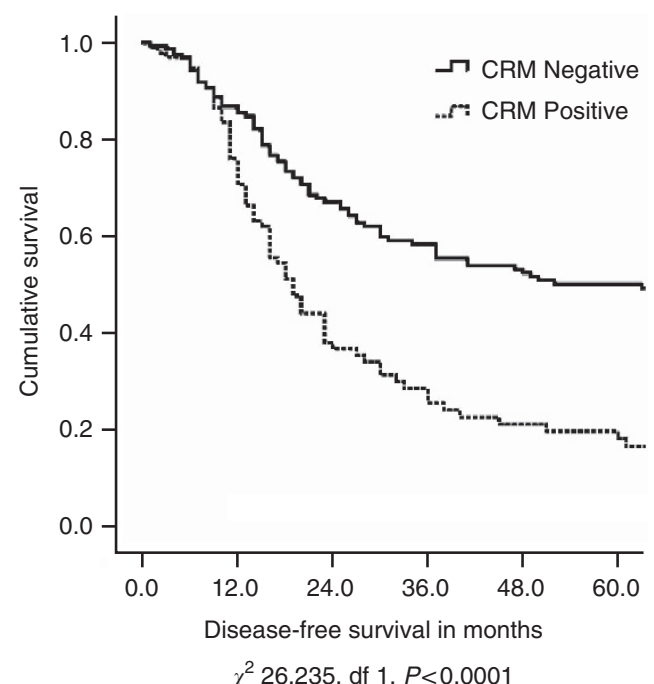

$\begin{array}{ccccccc}\text { No. at risk } & 0 & 12 & 24 & 36 & 48 & 60 \\ \text { month } & \text { months } & \text { months } & \text { months } & \text { months } & \text { month }\end{array}$

$\begin{array}{lcccccc}\text { CRM -ve } & 160 & 129 & 93 & 78 & 69 & 61 \\ \text { CRM +ve } & 98 & 66 & 29 & 18 & 14 & 11\end{array}$

Figure 2 Disease-free survival related to CRM status for all patients. 
Table 3 Univariate analyses of factors influencing survival

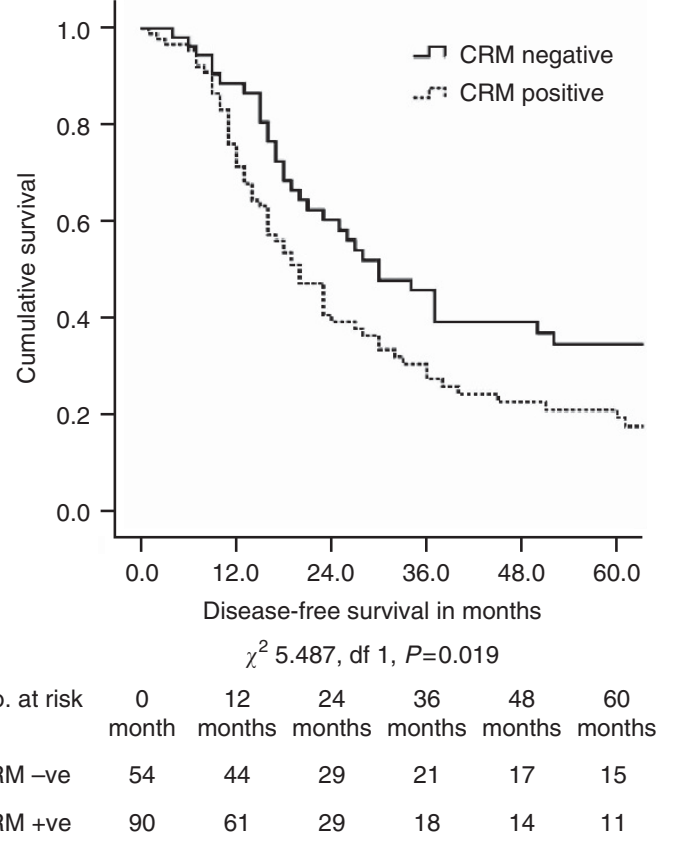

Figure 3 Disease-free survival related to CRM status for $\mathrm{PT} 3$ patients.

\section{Survival related to CRM status stratified by treatment type}

For patients treated with surgery alone, CRM - was associated with significantly better DFS (median: 74 vs 19 months, 2 year: 70.4 vs $41.5 \%, P<0.0001$ ) and OS (median: 77 vs 25, 2 year: 73.7 vs $58.8 \%, P=0.001$ ). For patients treated with CS, CRM - was associated with significantly better DFS (median: 30 vs 18 months, 2 year: 63.3 vs $35.5 \%, P=0.001$ ) and OS (median: 43 vs 26, 2 year: 68.2 vs $53.1 \%, P=0.004$ ). For patients treated with neoadjuvant chemoradiotherapy, CRM - was associated with trends towards better DFS (median: 49 vs 23 months, 2 year: 66.7 vs 20.0\%, $P=0.345$ ) and OS (median: 64 vs 26 months, 2 year: 69.4 vs $60.0 \%$, $P=0.363$ ), although the number of patients treated in this way was small $(n=42)$.

\section{Univariate and multivariate survival analyses}

A univariate analysis of clinical and pathological factors influencing both disease-free and OS is shown in Table 3. The same six factors were identified as significant for both the measures of survival, and were entered into multivariate analyses, with individual models for disease-free and OS (Table 4). Additional multivariate analyses were performed with stratification by treatment type for patients treated with surgery and CS (Table 4). The relatively small number of patients treated with neoadjuvant chemoradiotherapy precluded meaningful multivariate analysis of this subgroup. For all patients lymphovascular invasion and CRM + were independently and significantly associated with both measures of survival. In addition, for all patients the pathological lymph node metastasis count was independently and significantly associated with DFS, but did not reach statistical significance for OS $(P=0.051)$.

\section{Cancer recurrence related to CRM status}

The assessment of oesophageal cancer recurrence excluded patients who died in hospital (in-hospital mortality) and those in whom CRM status was not reported. CRM + was associated with a significantly higher incidence of cancer recurrence than CRM - (67 of 94 vs 63 of 152, 71.3 vs $41.4 \%, P<0.0001)$.

\begin{tabular}{|c|c|c|c|c|c|c|}
\hline \multirow[b]{2}{*}{ Factor } & \multicolumn{3}{|c|}{ Disease-free survival } & \multicolumn{3}{|c|}{ Overall survival } \\
\hline & HR & $95 \% \mathrm{Cl}$ & $P$-value & HR & $95 \% \mathrm{Cl}$ & $P$-value \\
\hline Age (years) & 1.011 & $0.995-1.028$ & 0.181 & 1.011 & $0.995-1.028$ & 0.174 \\
\hline Gender & 1.283 & $0.867-1.900$ & 213 & 1.296 & $0.874-1.920$ & 0.197 \\
\hline \multicolumn{7}{|c|}{ Year of treatment } \\
\hline 1998-99 & \multicolumn{2}{|c|}{ Reference group } & \multicolumn{4}{|c|}{ Reference group } \\
\hline 2000-01 & 1.701 & $0.722-4.006$ & 0.224 & 1.79| & $0.651-4.655$ & 0.269 \\
\hline $2002-03$ & 2.205 & $0.969-5.017$ & 0.059 & 2.284 & $0.882-5.915$ & 0.089 \\
\hline 2004-05 & 1.977 & $0.880-4.445$ & 0.099 & 2.034 & $0.794-5.213$ & 0.139 \\
\hline $2006-$ & 2.097 & $0.920-4.780$ & 0.078 & 2.195 & $0.846-5.692$ & 0.106 \\
\hline 2008 & 1.593 & $0.644-3.938$ & 0.313 & 1.704 & $0.612-4.746$ & 0.308 \\
\hline $2010-11$ & 2.178 & $0.809-5.867$ & 0.123 & 2.104 & $0.684-6.474$ & 0.195 \\
\hline Path cell type & 0.785 & $0.528-1.168$ & 0.233 & 0.810 & $0.544-1.206$ & 0.300 \\
\hline $\begin{array}{l}\text { Any neo } \\
\text { treatment }\end{array}$ & 1.128 & $0.818-1.557$ & 0.463 & 1.075 & $0.777-1.486$ & 0.663 \\
\hline \multicolumn{7}{|l|}{ Treatment type } \\
\hline $\mathrm{s}$ & \multicolumn{2}{|c|}{ Reference group } & \multicolumn{4}{|c|}{ Reference group } \\
\hline CS & 1.194 & $0.847-1.682$ & 0.312 & 1.144 & $0.809-1.617$ & 0.446 \\
\hline CRTS & 0.980 & $0.620-1.548$ & 0.931 & 0.925 & $0.585-1.462$ & 0.737 \\
\hline \multicolumn{7}{|l|}{ pT stage } \\
\hline CPR & \multicolumn{2}{|c|}{ Reference group } & \multicolumn{4}{|c|}{ Reference group } \\
\hline $\mathrm{TI}$ & 0.625 & & 0.297 & 0.670 & & 0.375 \\
\hline $\mathrm{T} 2$ & 1.760 & $0.797-3$ & 0.162 & 1.875 & $0.849-4.143$ & 0.120 \\
\hline T3 & 2.315 & $1.123-4.774$ & 0.023 & 2.297 & $1.113-4.738$ & 0.024 \\
\hline T4 & 3.959 & $1.367-11.467$ & 0.011 & 3.869 & $1.335-11.208$ & 0.013 \\
\hline pN stage & 2.435 & ।.75I-3.388 & $<0.0001$ & 2.336 & $1.675-3.258$ & $<0.0001$ \\
\hline \multicolumn{7}{|l|}{ Tumour grade } \\
\hline Well & \multicolumn{2}{|c|}{ Reference group } & \multicolumn{4}{|c|}{ Reference group } \\
\hline Moderate & 3.024 & $1.314-6.960$ & 0.009 & 2.830 & $1.229-6.516$ & 0.015 \\
\hline Poor & 4.157 & $1.801-9.595$ & 0.001 & 4.035 & $1.746-9.328$ & 0.001 \\
\hline $\begin{array}{l}\text { CRM } \\
\text { involvement }\end{array}$ & 2.263 & $1.637-3.130$ & $<0.0001$ & 2.139 & $1.541-2.969$ & $<0.000$ । \\
\hline LV invasion & 2.861 & $2.015-4.060$ & $<0.0001$ & 2.803 & $1.965-3.997$ & $<0.000$ । \\
\hline LNMC & 1.115 & $1.074-1.158$ & $<0.000$ & & & \\
\hline
\end{tabular}

Abbreviations: $95 \% \mathrm{Cl}=95 \%$ confidence interval; $C P R=$ complete pathological response; $C R M=$ circumferential resection margin; $C R T S=$ neoadjuvant chemoradiotherapy; $C S=$ neoadjuvant chemotherapy; $H R=$ hazard ratio; $L N M C=$ lymph node metastasis count; $\mathrm{LV}=$ lymphovascular; neo = neoadjuvant; path $=$ pathological; $\mathrm{S}=$ surgery alone.

\section{CRM status related to EUS-defined T stage}

The overall rates of CRM + related to EUS-defined T stage were T1 (0), T2 (7 of $46,15.2 \%$ ), T3 (81 of $165,49.1 \%$ ), T4 (6 of 16, 37.5\%). For patients treated with surgery alone these CRM + rates were T1 (0), T2 (2 of $33,6.1 \%)$, T3 (28 of $39,71.8 \%)$ and T4 (NA). For patients treated with CS, the equivalent rates were T1 $(0), \mathrm{T} 2$ (5 of $12,41.7 \%)$, T3 (49 of 93, 52.7\%) and T4 (5 of 9, 55.6\%). For patients treated with neoadjuvant chemoradiotherapy, the CRM + rates were $\mathrm{T} 1(\mathrm{NA}), \mathrm{T} 2(0), \mathrm{T} 3(4$ of $33,12.1 \%)$ and $\mathrm{T} 4$ (1 of 7 , $14.3 \%)$. The reduced CRM + rate for EUS T3 tumours following neoadjuvant chemoradiotherapy $(12.1 \%)$, compared with surgery alone $(71.8 \%)$, and CS (52.7\%) was highly statistically significant $(P<0.0001)$.

\section{CRM status related to pathological T stage}

The overall rates of CRM + related to pT stage were T1 (0), T2 ( 4 of $44,9.1 \%)$, T3 (90 of $144,62.5 \%)$, T4 (4 of 5, 80\%). The rates of $\mathrm{CRM}+$ in the 144 patients with pT3 tumours related to neoadjuvant treatment type were: surgery (28 of $44,63.6 \%)$, CS (58 of $86,67.4 \%$ ) and neoadjuvant chemoradiotherapy (4 of 14 , $28.6 \%, P=0.020)$. 
Table 4 Multivariate analyses of factors influencing survival

\begin{tabular}{|c|c|c|c|}
\hline & Hazard ratio & $95 \% \mathrm{Cl}$ & $P$-value \\
\hline \multicolumn{4}{|l|}{ Disease-free survival } \\
\hline \multicolumn{4}{|l|}{ All patients } \\
\hline Lymphovascular invasion & 2.087 & $1.396-3.122$ & $<0.0001$ \\
\hline CRM involvement & 1.762 & $1.201-2.586$ & 0.004 \\
\hline LNMC & 1.563 & $1.018-2.400$ & 0.041 \\
\hline \multicolumn{4}{|l|}{ Surgery alone } \\
\hline Lymphovascular invasion & 2.360 & $1.135-4.910$ & 0.022 \\
\hline \multicolumn{4}{|l|}{ pT stage } \\
\hline $\mathrm{TI}$ & Reference group & & \\
\hline $\mathrm{T} 2$ & 4.316 & $1.356-13.734$ & 0.013 \\
\hline $\mathrm{T} 3$ & 3.887 & $1.374-11.00 \mid$ & 0.011 \\
\hline \multicolumn{4}{|l|}{ Neoadjuvant chemotherapy } \\
\hline Lymphovascular invasion & 2.338 & $1.408-3.884$ & 0.001 \\
\hline LNMC & 2.323 & 1.282-4.209 & 0.005 \\
\hline CRM involvement & 1.892 & $1.123-3.189$ & 0.017 \\
\hline \multicolumn{4}{|l|}{ Overall survival } \\
\hline \multicolumn{4}{|l|}{ All patients } \\
\hline Lymphovascular invasion & 2.160 & $1.432-3.259$ & $<0.0001$ \\
\hline CRM involvement & 1.514 & $1.000-2.292$ & 0.050 \\
\hline LNMC & 1.054 & $1.000-1.112$ & 0.051 \\
\hline \multicolumn{4}{|l|}{ Surgery alone } \\
\hline Lymphovascular invasion & 2.204 & $|.06|-4.58 \mid$ & 0.034 \\
\hline \multicolumn{4}{|l|}{ pT stage } \\
\hline $\mathrm{TI}$ & Reference group & & \\
\hline $\mathrm{T} 2$ & 4.263 & $1.336-13.603$ & 0.014 \\
\hline T3 & 3.763 & $1.327-10.676$ & 0.013 \\
\hline \multicolumn{4}{|l|}{ Neoadjuvant chemotherapy } \\
\hline Lymphovascular invasion & 2.244 & $1.303-3.863$ & 0.004 \\
\hline LNMC & 1.073 & $1.016-1.132$ & 0.011 \\
\hline
\end{tabular}

Abbreviations: $95 \% \mathrm{Cl}=95 \%$ confidence interval; $\mathrm{CRM}=$ circumferential resection margin; LNMC = lymph node metastasis count.

\section{Influence of EUS derived factors on CRM involvement}

The results of univariate and multivariate binary logistic regression analysis of the association between various EUS derived factors and subsequent CRM involvement are presented in Table 5. Neoadjuvant treatment type was also included in this analysis, because of the significant influence on CRM outlined above. Other baseline patient factors including age, gender and pathological cell type were analysed and found to have no association with CRM involvement on univariate analysis. All factors significant on univariate analysis were entered into the multivariate model. The only EUS variable that retained an independent association with $\mathrm{CRM}+$ was EUS T stage, with an almost 25 -fold increased risk of $\mathrm{CRM}+$ once a tumour was deemed to be of endosonographic stage $\mathrm{T} 3$ or greater.

\section{Operative morbidity and mortality}

The overall rates of operative morbidity after surgery alone, CS and neoadjuvant chemoradiotherapy were 46 (44.7\%), 53 (42.7\%) and $21(50.0 \%)$, respectively $(P=0.747)$. Thirty day (operative) mortality rates were $5(4.9 \%), 1(0.8 \%)$ and $5(11.9 \%)$, respectively $(P=0.006)$. Ninety-day mortality rates were $7(6.8 \%), 1(0.8 \%)$ and $5(11.9 \%)$, respectively $(P=0.007)$. The in-hospital mortality rates were $7(6.8 \%), 1(0.8 \%)$ and $5(11.9 \%)$, respectively $(P=0.007)$.

\section{DISCUSSION}

This study represents the third largest report of the prognostic significance of CRM involvement following oesophagectomy, and the only one to address the potential value of EUS in predicting a threatened CRM. The principal findings were that a positive CRM
Table 5 Analysis of pre-treatment factors associated with circumferential margin involvement

\begin{tabular}{lccc}
\hline Factor & Odds ratio & $\mathbf{9 5 \%} \mathbf{~ C l}$ & P-value \\
\hline Univariate analysis & & & \\
EUS T stage & & & \\
TI/T2 & Reference group & & \\
T3/T4 & 8.726 & $3.798-20.050$ & $<0.0001$ \\
EUS N stage & & & \\
NO & Reference group & & 0.029 \\
NI & 1.781 & $1.060-2.992$ & 0.003 \\
EUS tumour length & 1.173 & $1.056-1.303$ & 0.020 \\
EUS disease length & 1.087 & $1.013-1.167$ & 0.061 \\
EUS tumour thickness & 1.795 & $0.974-3.309$ & \\
EUS LNMC & 1.156 & $1.033-1.294$ & 0.012 \\
Neo Tx & & & \\
S & Reference group & & \\
CS & 2.468 & $1.410-4.322$ & 0.002 \\
CRTS & 0.310 & $0.111-0.869$ & 0.026 \\
Multivariate analysis & & & \\
EUS T stage & & & \\
TI/T2 & Reference group & & \\
T3/T4 & 24.313 & $7.438-79.476$ & $<0.0001$ \\
Neo Tx & & & \\
S & Reference group & & \\
CS & 0.641 & $0.289-1.420$ & 0.273 \\
CRTS & 0.116 & $0.035-0.382$ & $<0.0001$ \\
\hline
\end{tabular}

Abbreviations: $95 \% \mathrm{Cl}=95 \%$ confidence interval; $C R M=$ circumferential resection margin; CRTS = neoadjuvant chemoradiotherapy; $C S=$ neoadjuvant chemotherapy; EUS = endoluminal ultrasonography; LNMC = lymph node metastasis count; neo Tx = neoadjuvant treatment type; $S=$ surgery alone.

was independently and significantly associated with disease-free and OS, for tumours of all pT stages, as well as pT3 stage. The co-finding of lymphovascular invasion and lymph node metastasis count as important independent prognostic factors is in keeping with the literature (Von Rahden et al, 2005; Mariette et al, 2008) and lends further credibility to this series. Several EUS factors were associated with a CRM +, but endosonographic $\mathrm{T}$ stage was the strongest, with almost half of all patients with EUS T3 tumours proving subsequently to have a positive CRM. A positive CRM was significantly less common after neoadjuvant chemoradiotherapy than CS for patients diagnosed with endosonographic T3 tumours.

The literature related to oesophageal CRM status is heterogeneous and conclusions inconsistent. Reports vary regarding study design, the use of neoadjuvant therapy, surgical technique, pathological processing and definition of CRM +. Eight studies report a negative survival association with CRM + on multivariate analysis, whereas seven others, including the two largest, failed to demonstrate an independent survival association with CRM status. Khan et al (2003) report no association with survival, despite having the largest sample size, but their 329 patients were treated between 1987 and 1996, and none received neoadjuvant treatment, yet their reported CRM + rate was the lowest at 20\%, which questions the accuracy of the histological assessment. More recently Mirnezami et al (2010) reported a series of 314 patients which identified CRM status as associated with survival on univariate analysis, but not multivariate analysis. However, this report included patients with positive longitudinal resection margins, a possible additional confounding factor.

The study has several potential weaknesses. The reporting of histological factors was undertaken by three separate pathology departments within the cancer network, and there could therefore be discrepancies in the reporting of CRM, particularly considering the difficulties related to this. However, the rates of CRM involvement lie within the range reported in published series, and it therefore seems unlikely that CRM involvement was 
substantially under reported. Moreover, the pathologists involved with the reporting of CRM status were effectively 'blind' to a degree, as they were unaware at the time that these data would be analysed in a future retrospective study. Although the numbers in this study are relatively large, they are not large enough and subsequently underpowered for subgroup analyses. This prevented exclusive analysis of patients with endosonographic T3 tumours, to establish the relative influence of the radiological factors other than EUS T stage, that may be predictive of CRM involvement. The comparison of different neoadjuvant modalities is also open to bias, as these treatments were allocated on a non-randomised, per patient basis, and according to MDT practice at the time.

In contrast the study has several strengths, as it represents real life stage-directed practice in a regional upper GI cancer network multidisciplinary team serving a population of 1.4 million over a 14-year period. All treatment was provided by an MDT experienced in the management of oesophageal cancer, whose results have been well audited (Morgan et al, 2007). The EUS component of this study represents particularly original work, and constitutes the only report comparing EUS factors with CRM status, relating this to the effects of neoadjuvant treatment. The radiological expertise involved in the EUS examinations has been well documented and the follow-up data are particularly robust with dates of death obtained from the Office for National Statistics. The role of imaging in predicting oesophageal CRM status is at an embryonic stage of development when compared with rectal CRM status, where MRI offers greater accuracy than EUS in determining a threatened CRM (Lahaye et al, 2005). Early reports suggest potential for MRI to enhance oesophageal cancer staging protocols (Riddell et al, 2006), but at present the thin-walled oesophagus, the proximity of adjacent other mediastinal structures, in particular the heart (necessitating cardiac gating), poses specific and considerable challenges. It is likely that EUS will remain the mainstay of locoregional staging for oesophageal cancer for some time, and therefore any potential role for EUS in predicting CRM involvement deserves further research.

From a histopathology perspective the assessment of the oesophageal CRM is controversial. Although debate continues as to the significance of CRM, pathological lymph node stage is an established prognostic factor. It has been suggested that accurate assessment of both lymph node stage and CRM status are incompatible, and compromise is required (Mapstone, 2007). In particular, the dissection of lymph nodes from the resected specimen by some surgeons renders meaningful assessment of the CRM impossible (Mapstone, 2007). The precise criteria used to define CRM + is another area of controversy. Whereas in the United Kingdom this is defined as the presence of tumour within $1 \mathrm{~mm}$ of the CRM by the Royal College of Pathologists (RCP) (Mapstone, 1998), in the United States the College of American Pathologists (CAP) use a definition of the presence of tumour at the margin itself (Washington et al, 2009). Comparative studies have identified differences in the relative prognostic value of CRM status, depending on the definition used, with support for both the RCP (Pultrum et al, 2010; Rao et al, 2012; Salih et al, 2012) and the CAP (Deeter et al, 2009; Verhage et al, 2011; Harvin et al, 2012) definitions.

Most patients in the United Kingdom present with T3 disease, for which neoadjuvant chemotherapy followed by surgery is the current standard of care. On the basis of these results, patients treated this way have a $52.7 \%$ chance of a circumferentially incomplete (R1) resection. These results also suggest the possibility of significantly improved odds $(87.5 \%)$ of a circumferentially complete (R0) resection when treated with neoadjuvant chemoradiotherapy, an option already considered to be the neoadjuvant modality of choice in the United States (Hingorani et al, 2011). The recent Dutch CROSS randomised trial reported an R0 resection rate of $92 \%$ associated with neoadjuvant chemoradiotherapy, significantly higher than the $69 \%$ achieved with surgery alone (van Hagen et al, 2012). Moreover, neoadjuvant chemoradiotherapy resulted in a complete pathological response in $29 \%$ of patients and was associated with a two-fold increase in median survival from 24.0 to 49.4 months, when compared with oesophagectomy alone (van Hagen et al, 2012). The issue of an involved CRM therefore forms an integral part of the much wider argument relating to the most appropriate neoadjuvant therapy regimes for patients with operable yet locally advanced oesophageal cancer. CS and chemoradiotherapy have both demonstrated clear survival advantages over surgery alone in meta-analyses (Urschel and Vasan 2003; Sjoquist et al, 2011), yet there is little high-quality data comparing these two neoadjuvant modalities to each other. Only two randomised trials have addressed this question (Stahl et al, 2009; Burmeister et al, 2011). Meta-analysis of both showed an insignificant trend towards improved survival with chemoradiotherapy (Sjoquist et al, 2011). There was no association between the type of neoadjuvant treatment and the risk of post-operative mortality, but both trials closed early and were consequently underpowered.

\section{CONCLUSION}

Involvement of the oesophageal CRM is an independently significant predictor of poorer disease-free and OS. Assuming appropriately radical surgery has been performed, an involved CRM can be considered more a marker of locoregionally advanced disease, than suboptimal surgery. There is a clear and pressing need for an adequately powered randomised trial of neoadjuvant chemoradiotherapy $v s$ chemotherapy in operable oesophageal cancer, and indeed this has recently been proposed in the United Kingdom (Hingorani et al, 2011). The findings of this study further support this proposition and suggest that patients with endosonographic T3 tumours should be targeted.

\section{REFERENCES}

Adam IJ, Mohamdee MO, Martin IG, Scott N, Finan PJ, Johnston D, Dixon MF, Quirke P (1994) Role of circumferential margin involvement in the local recurrence of rectal cancer. Lancet 344(8924): 707-711

Allum WH, Stenning SP, Bancewicz J, Clark PI, Langley RE (2009) Longterm results of a randomized trial of surgery with and without preoperative chemotherapy in esophageal cancer. J Clin Oncol 27(30): 5062-5067

Burmeister B, Thomas JM, Burmeister EA, Walpole ET, Harvey JA, Thomson DB, Barbour AP, Gotley DC, Smithers BM (2011) Is concurrent radiation therapy required in patients receiving preoperative chemotherapy for adenocarcinoma of the oesophagus? A randomised phase II trial. Eur J Cancer 47(3): 354-360

Chao YK, Yeh CJ, Chang HK, Tseng CK, Chu YY, Hsieh MJ, Wu YC, Liu HP (2011) Impact of circumferential resection margin distance on locoregional recurrence and survival after chemopradiotherapy in esophageal squamous cell carcinoma. Ann Surg Oncol 18(2): 529-534

Deeter M, Dover R, Kuppusamy MK, Koehler RP, Low DE (2009) Assessment of criteria and clinical significance of circumferential resection margins in esophageal cancer. Arch Surg 144(7): 618-624

Dexter SP, Sue-Ling H, McMahon MJ, Quirke P, Mapstone N, Martin IG (2001) Circumferential resection margin involvement; an independent predictor of survival following surgery for oesophageal cancer. Gut 48(5): 667-670

Griffiths EA, Brummell Z, Gorthi G, Pritchard SA, Welch IM (2006) The prognostic value of circumferential resection margin involvement in oesophageal malignancy. Eur J Surg Oncol 32(4): 413-419 
Harvin JA, Lahat G, Correa AM, Lee J, Maru D, Ajani J, Marom EM, Welsh J, Bhutani MS, Walsh G, Roth J, Mehran R, Vaporciyan A, Rice D, Swisher S, Hofsetter W (2012) Neoadjuvant chemoradiotherapy followed by surgery for esophageal adenocarcinoma: significance of microscopically positive circumferential radial margins. J Thorac Cardiovasc Surg 143(2): 412-420

Hingorani M, Crosby T, Maraveyas A, Dixit S, Bateman A, Roy R (2011) Neoadjuvant chemoradiotherapy for resectable oesophageal and gastrooesophageal junction cancer-do we need another randomised trial? Clin Oncol 23(10): 696-705

Khan OA, Fitzgerald JJ, Soomro I, Beggs FD, Morgan WE, Duffy JP (2003) Prognostic significance of circumferential margin resection margin involvement following oesophagectomy for cancer. Br J Cancer 88(10): $1549-1552$

Klautke G, Feyerherd P, Ludwig K, Prall F, Foitzik T, Fietkau R (2005) Intensified concurrent chemoradiotherapy with 5-fluorouracil and irinotecan as neoadjuvant treatment in patients with locally advanced rectal cancer. Br J Cancer 92(7): 1215-1220

Lahaye MJ, Engelen SM, Nelemans PJ, Beets GL, van de Velde CJ, van Engelshoven JM, Beets-tan RG (2005) Imaging for predicting the risk factors-the circumferential resection margin and nodal disease-of local recurrence in rectal cancer: a meta-analysis. Semin Ultrasound CT MR 26(4): 259-268

Mapstone NP. Dataset for the Histopathological Reporting of Oesophageal Carcinoma. Royal College of Pathologists: London (1998)

Mapstone NP. Dataset for the Histopathological Reporting of Oesophageal Carcinoma. 2nd edn. Royal College of Pathologists: London (2007)

Mariette C, Piessen G, Briez N, Triboulet JP (2008) The number of metastatic lymph nodes and the ratio between metastatic and examined lymph nodes are independent prognostic factors in esophageal cancer regardless of neoadjuvant chemoradiation or lymphadenectomy extent. Ann Surg 247(2): 365-371

Medical Research Council Oesophageal Cancer Working Group (2002) Surgical resection with or without preoperative chemotherapy in oesophageal cancer; a randomised controlled trial. Lancet 359(9319): $1727-1733$

Mirnezami R, Rohatgi A, Sutcliffe RP, Hamouda A, Chandrakumaran K, Botha A, Mason RC (2010) Multivariate analysis of clinicopathological factors influencing survival following esophagectomy for cancer. Int J Surg 8(1): 53-63

Morgan MA, Lewis WG, Crosby TDL, Escofet X, Roberts SA, Brewster AE, Harvard TJ, Clark GW (2007) Prospective cohort comparison of neoadjuvant chemoradiotherapy versus chemotherapy for patients diagnosed with oesophageal cancer. Br J Surg 94(12): 1509-1514

NHS Information Centre (2010) National Oesophago-Gastric Cancer Audit 2010. http://www.ic.nhs.uk/ogreports (accessed 01 May 2012)

Pultrum BB, Honing J, Smit JK, van Dulleman HM, van Dam GM, Groen H, Hollema H, Plukker JT (2010) A critical appraisal of circumferential resection margins in esophageal carcinoma. Ann Surg Oncol 17(3): $812-820$

Rao VS, Yeung MM, Cooke J, Salim E, Jain PK (2012) Comparison of circumferential resection margin clearance criteria with survival after surgery for cancer of the esophagus. J Surg Oncol 105(8 745-749

Reynolds JV, Muldoon C, Hollywood D, Ravi N, Rowley S, O’Byrne K, Kennedy J, Murphy TJ (2007) Long-term outcomes following neoadjuvant chemoradiotherapy for esophageal cancer. Ann Surg 245(5): 707-716

Riddell AM, Hillier J, Brown G, King DM, Wotherspoon AC, Thompson JN, Cunningham D, Allum WH (2006) Potential of surface-coil MRI for staging of esophageal cancer. AJR Am J Roentgenol 187(5): 1280-1287
Sagar PM, Johnston D, McMahon MJ, Dixon MF, Quirke P (1993) Significance of circumferential resection margin involvement after oesophagectomy for cancer. Br J Surg 80(11): 1386-1388

Saha AK, Sutton C, Rotimi O, Dexter S, Sue-Link H, Sarela AJ (2009) Neoadjuvant chemotherapy and surgery for esophogeal adenocarcinoma: prognostic value of circumferential resection margin and stratification of N1 category. Ann Surg Oncol 16(5): 1364-1370

Scheepers JJG, van der Peet DL, Veenhof AA, Cuesta MA (2009) Influence of circumferential resetion margin on prognosis in distal esophageal and gastroesophageal cancer approached through the transhiatal route. Dis Esophagus 22(1): 42-48

Salih T, Jose P, Mehta SP, Mirza A, Udall G, Pritchard SA, Hayden JD, Grabsch HI (2012) Prognostic significance of cancer within $1 \mathrm{~mm}$ of the circumferential resection margin in oesophageal cancer patients following neo-adjuvant chemotherapy. Eur J Cardiothorac Surg; e-pub ahead of print 4 June 2012; doi:10.1093/ejcts/ezs331

Sjoquist KM, Burmeister BH, Smithers BM, Zalcberg JR, Simes RJ, Barbour A, Gebski V (2011) Survival after neoadjuvant chemotherapy or chemoradiotherapy for resectable oesophageal carcinoma: an updated meta-analysis. Lancet Oncol 12(7): 681-692

Stahl M, Walz MK, Stuschke M, Lehmann N, Meyer HJ, RieraKnorrenschild J, Langer P, Engenhart-Cabillic R, Bitzer M, Konigsrainer A, Buddach W, Wilke H (2009) Phase III Comparison of preoperative chemotherapy compared with chemoradiotherapy in patients with locally advanced adenocarcinoma of the esophagogastric junction. J Clin Oncol 27(6): 851-856

Sujendran V, Wheeler J, Baron R, Warren BF, Maynard N (2008) Effect of neoadjuvant chemotherapy on circumferential margin positivity and its impact on prognosis in patients with resectable oesophageal cancer. Br J Surg 95(2): 191-194

Thompson SK, Ruszkiewicz AR, Jamieson GG, Esterman A, Watson DI, Wijnhoven BP, Lamb PJ, Devitt PG (2008) Improving the accuracy of TNM staging in esophageal cancer: a pathological review of resected specimens. Ann Surg Oncol 15(12): 3447-3458

Urschel JD, Vasan H (2003) A meta-analysis of randomized controlled trials that compared neoadjuvant chemoradiation and surgery to surgery alone for resectable esophageal cancer. Am J Surg 185(6): 538-543

van Hagen P, Hulshof MC, van Lanschot JJ, Steyerberg EW, van Berge Henegouwen MI, Wijnhoven BP, Richel DJ, Nieuwenhuijzen GA, Hospers GA, Bonenkamp JJ, Cuesta MA, Biaisse RJ, Busch OR, ten Kate FJ, Creemers GJ, Punt CJ, Plukker JT, Verheul HM, Spillenaar Bilgen EJ, van Dekken J, van der Sangen MJ, Rozema T, Biermann K, Beukema JC, Piet AH, van Rij CM, Reinders JG, Tilanus HW, van der Gaast A, CROSS Group (2012) Preoperative chemoradiotherapy for esophageal or junctional cancer. N Engl J Med 366(22): 2074-2084

Verhage RJ, Zandvoort HJ, ten Kate FJ, van Hillegersberg R (2011) How to define a positive circumferential resection margin in T3 adenocarcinoma of the esophagus. Am J Surg Pathol 35(6): 919-926

Von Rahden BH, Stein HJ, Feith M, Becker K, Siewert JR (2005) Lymphatic vessel invasion as a prognostic factor in patients with primary resected adenocarcinoms of the esophagogastric junction. J Clin Oncol 23(4): 874-879

Washington K, Berlin J, Branton P, Burgart LJ, Carter DK, Fitzgibbons P, Frankel WL, Jessup J, Kakar S, Minsky B, Nakhleh R, Compton CC (2009) Protocol for the Examination of Specimens From Patients With Carcinoma of the Esophagus. College of American Pathologists. http:// www.cap.org/apps/docs/committees/cancer/cancer_protocols/2009/ Esophagus_09protocol.pdf (accessed 1 May 2012)

Weaver S, Blackshaw G, Lewis WG, Edwards P, Roberts SA, Thomas GV (2004) Comparison of special interest computerised tomography, endosonography and histopathological stage of oesophageal cancer. Clin Radiol 59(6): 499-504

This work is published under the standard license to publish agreement. After 12 months the work will become freely available and the license terms will switch to a Creative Commons Attribution-NonCommercial-Share Alike 3.0 Unported License. 